Motrivivência Ano XXII, No 34, P. 170-185 Jun./2010

DOI:10.5007/2175-8042.2010n34p170

\title{
PRÁTICAS CORPORAIS, EXPERIÊNCA E REALIDADE VIRTUAL: notas introdutórias
}

\author{
Ana Paula Salles da Silva' \\ Ari Lozzorotti Filho² \\ Ana Márcia Silva ${ }^{3}$
}

\begin{abstract}
Resumo
O presente ensaio introduz alguns elementos para a reflexão acerca da relação entre três conceitos complexos, densos e, em certa medida, paradoxais,

quais sejam: as práticas corporais, a experiência e a virtualização. $\mathrm{O}$ texto aponta para a relevância dessa discussão para os campos da Educação

Física e do Lazer, sobretudo, porque as práticas corporais virtualizadas

Abstract

The present essay introduces some elements for reflection regarding the relationship between three complex concepts that are in a certain way dense and paradoxical: body practices, experience and virtualization. The present text aims at discussing the relevance of these concepts in the fields of physical education and leisure, mainly, because virtualized body

1 Professora da Universidade Federal de Goiás. Mestre em Educação Física pela Universidade Federal de Santa Catarina (2005) e atualmente é doutoranda em Educação Física pela mesma instituição. Contato: aninhasalless@msn.com.

2 Professor na Faculdade de Educação Física da Universidade Federal de Goiás, é Mestre em Educação (2002) pela mesma instituição. Atualmente é doutorando em Educação Física na Universidade Federal de Santa Catarina. Contato: arilazzarotti@gmail.com.

3 Professora Faculdade de Educação Física da Universidade Federal de Goiás, Pós-doutora pela Universitat de Barcelona (2006). Foi Presidenta do Colégio Brasileiro de Ciências do Esporte (2003-2005). Atualmente, é Editora da Revista Pensar a Prática e membro de Corpo Editorial e Revisora de vários periódicos. Coordenadora do Laboratório Physis de Pesquisa em Educação Física, Sociedade e Natureza, membro do Núcleo de Estudos Pedagógicos em Educação Física e integrante da Rede Cedes de Pesquisa - Ministério do Esporte. Contato: amarciasi@gmail.com.
\end{abstract}


introduzem novos elementos na discussão acerca do conceito de experiência, além de promover uma modificação da percepção subjetiva sobre as práticas corporais nãovirtualizadas e, mais amplamente, sobre toda formação humana.

Palavras chaves: práticas corporais, experiência, virtualização.

$\mathrm{Na}$ atualidade, as práticas corporais vêm sendo apresentadas por outra rede de possíveis, aquela constituída pelas novas tecnologias aplicadas ao lazer e a educação. São novos artefatos tecnológicos que intencionam virtualizar a experiência lúdica permitida pelas práticas corporais.

A virtualização do esporte por meio dos games é um exemplo dessa nova forma possível de vivenciar a realidade. As características conquistadas em cada etapa do jogo colocam seus usuários além dos limites postos pela materialidade corporal, provocando o desejo da superação e, de forma sutil e nem sempre consciente, um descontentamento com a dimensão corpórea no espaço não virtual. No espaço virtual é possível ser "super-humanos" ou "semideuses" dotados de potencialidades mágicas. Ali, não é preciso morrer, ter medo de errar ou preocupar-se ética e moralmente. Nesse campo da virtualidade, tudo se constitui como um devir, num incessante recomeçar. practices introduce new elements for discussion concerning the concept of experience. Besides they promote a change in the subjective perception on non-virtualized body practices, and in a more broaden view, about human education.

Key-words: body practices, experience, vitualization

Outro exemplo destas novas possibilidades na chamada "realidade líquida" (BAUMAN, 2001), maleável e elástica, mas nem por isso menos real para quem a vivencia, é o ciber-espaço, com suas inúmeras possibilidades. Sem negar o potencial inerente a essa realidade virtual para a produção, assim como também para o acesso a informação e ao conhecimento, faz-se necessário refletir em que medida esse tipo de realidade torna-se indutor de certa insatisfação. Num processo cíclico, tal insatisfação pode estar compelindo os sujeitos a buscarem nas novas formas de relações mediadas pela máquina-computador aquilo que parece estar ausente nas relações humanas cotidianas. O fato é que se torna cada vez mais evidente que crianças e jovens de diferentes classes sociais fazem uso cotidiano de mini-games, games, sites de sociabilidades e entretenimento como o orkut, facebook, entre outros equipamentos "virtuais" que possibilitam uma second 
life, seja nos seus lares, em casas de amigos ou em casas de jogos, as lanhouses. Tal como elas, os adultos também participam dessas práticas virtuais em seu espaço/tempo de lazer, onde várias formas de prazer, diga-se também sexual, encontram espaço privilegiado.

Nesse sentido, a emergência da liberação corporal com suas exigências, novas normas de ser, podem ser indicadores de um tipo de fuga peculiar da corporalidade. Acreditamos que os jogos virtuais e o ciberespaço sejam possibilidades - induzidas pela lógica do consumo - as quais as pessoas buscam para ser não sendo o que se é, negando o corpo sob argumentos como o risco a ser evitado, suas limitações e fragilidades ou sua não correspondência as expectativas sociais, o que nos torna passíveis de crítica e rejeição, talvez, na perspectiva do que nos alertam autores como Beck (1998), Spink (2001, 2003, 2008). Em outras palavras falamos das múltiplas identidades e personagens as quais as pessoas apropriam-se ou criam para si e que, em certa medida, visam alcançar diferentes modelos de corpo e estilos de vida numa projeção fictícia de si.

A grande penetração de expectativas e imagens de corpos masculinos e femininos idealizados, as quais são inatingíveis para a maior parte dos sujeitos, pode ser uma possibilidade de compreender um crescente número de usuários do mundo virtual, neste âmbito do lazer. Essa esfera virtual permite, tanto potencializar o corpo ao assumir os super-poderes permitidos nesses jogos, como livrar-se dos limites concretos da materialidade corporal, ao se virtualizar no ciber-espaço.

Observamos, assim, a ascensão de um novo dualismo, uma das mais fortes características da modernidade. Nessa nova perspectiva dualista, ser humano virtual e não-virtual confrontam-se e tensionam identidades, tanto quanto complementam-se e interagem. Os limites do corpo não são mais, necessariamente, os limites do ser humano, ao menos naquilo que the dá origem no imaginário social e que, nem por isso, deixa de ser real e ter uma força sobre os sujeitos. Este movimento dialético de tensão e complementação não acontece, porém, sem custos para o sujeito e pode gerar novo processo de coisificação do corpo, tornando-o cada vez mais secundário em relação ao eu que pode objetivar-se em um "avatar".

Nessa linha de reflexão, é preciso considerar que as experiências virtuais apresentam determinações sobre a formação humana, repercutindo na forma como as pessoas se concebem e agem. As experiências virtuais atravessam 
determinações fundamentais na construção dos sujeitos, em sua origem étnica e religiosa, assim como de classe e de gênero. Um indicador deste processo é o caso de segmento mundializado de jovens, os chamados "vídeokids, composto por jovens aficionados por jogos eletrônicos, que não são muito diferentes no que refere aos hábitos de consumo, seja em Tóquio ou em Londres". (MASCARENHAS, 2003, p. 128).

Nesses espaços mais diretamente interpelados pela virtualidade, o padrão normativo colocado não nos parece aquém ou além das expectativas impostas pela modenidade; pelo contrário, estão em consonância com a mesma, agregando valores de mercado e do modo de vida característico da ordem econômico-social capitalista. Compreender esta relação, porém, não significa dizer que não existam expressões de resistência e das diferenças, como a valorização da singularidade e o surgimento de novas sociabilidades, fenômenos que merecem ser mais bem investigados.

Compreendemos que a Educação Física, assim como o lazer, encontra-se tradicionalmente vinculada ao campo da experiência com as práticas corporais, ou seja, do saber fazer, tanto em sua formação profissional quanto nas várias intervenções sociais decorrentes, como identificaram anteriormente vários pesquisadores (SOARES, 1994; 1998, PAGNI, 1996; PAIVA, 2004). É nesse sentido que identificamos a necessidade de problematizar a constituição de uma experiência virtual crescente, sobretudo entre as novas gerações, em tensão com os conceitos de práticas corporais e de experiência. Essa problematização permitiria melhor compreender as relações que atravessam as práticas corporais não-virtualizadas, considerando suas decorrências para esse campo acadêmico-profissional e, mais amplamente, para o processo de formação humana que se encontra em curso.

\section{Práticas corporais e virtuali- zação}

Sibilia, (2002, p.42) indica a presença de duas teses acerca do corpo na atualidade, nessas circunstancias postas pelo avanço da tecnociência, as quais estariam relacionadas com a compreensão do mundo virtual: as de tradição prometéica e de tradição fáustica. A tese da tradição prometéica pretende dominar tecnicamente a natureza e busca fazê-lo justificando-se em prol do "bem humano", pela emancipação da espécie e, inclusive, das "classes oprimidas". Por outro lado, "a de tradição fáustica rejeita a organicidade e a materialidade do corpo humano para procurar - na 
sua superação - um ideal ascético, artificial, virtual, imortal".

Para a autora, se na tese de tradição prometéica o corpo é estimado, ainda que esta tradição seja sustentada na razão iluminista que busca o progresso da humanidade possível apenas com a dominação da natureza e, portanto, do próprio corpo; na tradição fáustica, pelo contrário, o corpo é negado por representar um problema para plenitude da vida humana, visto que este envelhece, fica doente e tem a morte como destino.

As duas tradições - fáustica e prometéica - possuem em comum o fato de estarem sustentadas na perspectiva da tecnociência e em sua perspectiva de predomínio sobre a dinâmica social:

A informática, as telecomunicações e as biotecnologias representam três áreas fundamentais da tecnociência contemporânea. (...) podemos afirmar que tais saberes - enquistados em claras relações de poder - estão contribuindo fortemente para a produção dos corpos e das almas deste início de século, apresentado um conjunto de promessas, temores, sonhos e realizações inteiramente novos." (SIBILIA, 2002, p. 11).

Levy (2002) afirma que as informações sempre seguiram o caminho dos corpos e foi com o advento das novas tecnologias que essas se separaram. Tal separação criou uma nova cultura, chamada de "cibercultura" e que estaria, segundo Kenski (2003), construindo uma educação "descorporizada". Essa realidade virtual, aparentemente desmaterializada, não representa, contudo, uma oposição ao real como se a mesma não existisse.

As práticas corporais virtualizadas são reais, e não devem ser consideradas uma "desrealização (transformação de uma realidade num conjunto de possíveis)", como indica Lévy (1996, p.17-18). Para esse autor, real e virtual não se contrapõem, sendo existências que se presentificam na realidade de maneiras diferentes. Nesse aspecto Rivoltela (2008, p. 45, grifo do autor) exemplificando as idéias de Levy, informa que "o mundo virtual de um videogame (...) ainda que goze de uma existência particular - por assim dizer, não em carne e osso -, de fato existe, porque caso contrário não se poderia jogar".

Sendo real a experiência com as práticas corporais virtuais, ainda que aparentemente descorporificada, trata-se agora de pensar de que natureza são essas experiências provocadas pelo processo de virtualização. Centrando a discussão na interação das pessoas com o ciberespaço e com jogos eletrônicos 
pode-se sugerir que esses mundos virtuais possibilitam a realização de coisas impossíveis à materialidade corporal, além de ser considerados movimentos de produção e criação e não de efetivação do considerado possível, pois enquanto o possível está pré-determinado pelo real apenas a espera de acontecer, os processos de virtualização exigem saídas inovadoras e criativas. (LEVY, 1996)

Essa possibilidade é contestada como premissa por Setzer (2001) pois, segundo ele, o jogo eletrônico elimina a complexidade do pensar ao exigir respostas automatizadas, ativando parcialmente $o$ sentir e direcionando-o apenas ao desafio e a competição, terminando, por fim, por automatizar também as ações. Para esse autor, o mesmo processo se daria com o computador, de modo mais geral, ao tomar de crianças e jovens um espaço/ tempo importante, direcionando seu desenvolvimento.

Por outro lado, quando consideramos o desempenho de atletas de alto nível ao realizar um gesto técnico específico durante um jogo de uma modalidade qualquer se percebe que apenas uma minoria conseguiria realizá-lo, em função do alto grau de especialização e treinamento envolvido. Tomemos o exemplo de alguns esportes convencionais: quando da cortada de fundo, atrás da linha dos três me- tros do voleibol, onde um jogador consegue com toda uma preparação física e o aperfeiçoamento do gesto técnico "cravá-la" na outra quadra, somos forçados a admitir que poucos teriam as mesmas condições objetivas para realizá-lo. E quando da beleza das faltas cobradas no ângulo por jogadores especialistas no futebol, é também um fato que nem todos conseguem fazê-lo, ainda que no chamado "país do futebol" o acesso a essa prática corporal seja maior do que a outros esportes. A especialidade desses gestos constitui uma performance que encanta observar pela dificuldade de execução, mobilizando diferente valores sociais e estéticos.

Tal percepção motiva a procura por diferentes meios e a partir de distintas intencionalidades tornar possível vivenciar esses gestos. Um desses meios que possibilita uma experiência com as sensações similares são aqueles propiciados pelos esportes virtualizados nos jogos eletrônicos. Enquanto a objetividade do corpo não permite que sejam realizados determinados movimentos como desejados, o corpo virtualizado fornece condições para que a pessoa que opera um vídeo-game, por exemplo, vislumbre algo da performance de um atleta de alto rendimento. Assim, em alguns games, além de escolher a celebridade esportiva com a qual se 
quer fazer representar e adquirir as habilidades técnicas deste jogador ao se manipular o joy-stick, tem-se a sensação de estar realizando as jogadas antes apenas observadas.

"Livre das coerções habituais diante de um mundo simplificado, cujas chaves são fáceis de manipular, o viajante virtual conhece de fato um mundo fictício, sente fisicamente um mundo sem carne. No universo de síntese, o jogo com a situação libera todas as aparências do verdadeiro sem o risco do teste real e com a faculdade de viver mil atividades inéditas. Apesar da reduzida mobilidade do sujeito, ele conhece uma plenitude sensorial que a sociedade não lhe prodigaliza com tanta largueza. (...) O indivíduo desloca-se concretamente em um universo constituído. Dissociando corpo e experiência, fazendo a relação com o mundo perder o caráter real e transformando-a em relação com o dado (...)." (LE BRETON, 2003, p. 143). (grifo nosso).

A associação entre corpo e experiência que acima destacamos, quando mediadas pelas experiências de sínteses virtuais, vai gradativamente sendo desfeita, conforme se amplia o tempo e profundidade desses simulacros virtuais. Em ou- tras palavras, não é uma negação da experiência, mas, talvez, uma negação do corpo. Trata-se de elevar a outra potencia a dicotomia entre corpo e espírito na experiência com as práticas corporais, na medida em que podemos viver a experiência da prática corporal através de uma experiência "sem corpo", dada a sua passividade no espaço das experiências com o virtual. O virtual intensifica a experiência, sobretudo aquela de ordem cognitiva, e a reafirma no corpo com a satisfação advinda das sensações.

A experiência no virtual constitui um diferencial, talvez um avanço, se considerada em relação às pessoas comuns, não atletas, com os limites postos por sua condição corporal e outros, não poderiam experenciar aqueles movimentos. Esse dado permite compreender as práticas corporais virtuais como uma possibilidade para a experiência humana, mas também e de forma ambígua, gera opções que possibilitam dispensar as práticas corporais não virtuais, pelo menos no que se refere à satisfação e o prazer.

Quanto à possibilidade de acesso a experiência é preciso frisar que se trata de uma forma de representação da experiência nas práticas corporais não virtuais e, enquanto representação, constitui-se numa outra experiência que não é 
igual a primeira, ainda que carregue elementos significativos dessa. A virtualização é "uma mutação de identidade, um deslocamento do centro de gravidade ontológico do objecto considerado: em vez de se definir principalmente por sua actualidade ('uma solução'), a entidade passa a encontrar sua consistência essencial num corpo problemático". (LÉVY, 1996, p.17 e18).

Citamos como exemplo, um campo da sociologia do esporte que o trata como representação da guerra, uma forma de lidar com pulsões humanas de forma controlada (ELIAS, 1992). O esporte moderno como representação da guerra e no qual a natureza humana deve ser controlada, um domínio instituído pela razão iluminista que constrói sofisticadas formas de treinamento corporal constitui-se a norma que permanece em voga (VAZ, 1999) e torna o esporte um dos principais fenômenos sociais da modernidade e faz da indústria cultural esportiva, das mais rentáveis do mundo.

As lutas, os jogos, as ginásticas e danças, entre outras práticas corporais, vão sendo gradativamente esportivizadas e o controle dos instintos humanos vai sendo desenvolvido, numa tentativa de humanização, a partir do exercício da razão, sobretudo em seu aspecto instrumental. O esporte é dos filhos mais pródigos da modernidade, guardando grande proximidade lógica e histórica com a era moderna, permitindo, entre outras coisas, a normalização da chamada natureza humana, ou o controle dos impulsos humanos, por meio de regras prédeterminadas, da justificação dos meios em relação aos fins.

Esporte e guerra evocam experiências diferentes com elementos comuns, ainda que o primeiro possa ser considerado um meio para a necessidade de vivenciar impulsos humanos de forma controlada. A idéia de controle estaria expressa agora mais efetivamente sobre certo âmbito da subjetividade, radicalizando-se a dissociação corpo e espírito (cognição). Poderíamos perguntar, nesse caso, ao termos uma representação do esporte nos jogos eletrônicos se estaríamos lidando com a mesma representação da guerra nessa versão contemporânea do esporte, porém, acentuada pela ausência do corpo, sublimado nessas experiências de síntese?

Essa questão é posta porque o virtual não é apenas um espaço-tempo onde acontece a experiência, mas constitui-se, também, em experiência. Como experiência, o controle dos impulsos humanos no espaço virtual não se coloca porque não há corpo, portanto, não há limites físicos, afetivos ou morais, naquilo que remete ao humano. 
É preciso lembrar, no caso das experiências com os jogos eletrônicos, que se está cindindo também aquilo que os limites do corpo constituem como possibilidades humanas inestimáveis, inclusive para o exercício de ser humano. Os limites corporais, a resistência da materialidade frente à lógica da racionalidade instrumental está, sobretudo, naquilo que permite "de alteridade, de abertura para o outro e para a solidariedade" (VAZ; SILVA; ASSMANN, 20 , p. 12). A inexistência de limites na experiência virtual potencializa outros modos de ser humano que se afastam desses preceitos.

As representações do esporte nos espaços de síntese não permitem apenas a experiência de gestualidades, mas também a constituição de uma nova forma de liberação, onde o controle que não passa diretamente pelo corpo, mas nele encontra-se inscrita.

Outras experiências em jogos interativos e com regras flexíveis e que não são necessariamente representações esportivas também, a nosso ver, promovem novas formas de liberação e controle; ocorre da mesma forma, na navegação pelo ciberespaço e em seus diferentes mundos, visto que as experiências virtuais serão sempre experiências de representações. A diferença colocada nessas experiências de representação está posta por um processo dinâmico de virtualização e atualização que se coloca em andamento nas práticas corporais virtualizadas e que exigem o despertar de novos saberes e ações que retroalimentam o virtual.

Essa nova forma de liberdade que promove tanto fascínio, vivida nos espaços de síntese e no ciberespaço, como expresso no início do texto, vem sendo construída e explorada exponencialmente no âmbito do mercado. A prática do consumo não se reflete não apenas na busca pela aquisição de bens para a realidade virtual ou de síntese, como o acesso a áreas restritas, compra de espaços/objetos virtuais, jogos, joysticks, entre outros, onde crianças, jovens e adultos são incitados cotidianamente pelas possibilidades que os colocam no rol de consumidores desse devir.

Essa nova forma de liberdade e incitação ao consumo, mais do que isso, estende-se para uma desqualificação ou qualificação das atividades que ocorrem fora e dentro do espaço/tempo virtual. Trata-se de uma transformação na forma como a realidade é percebida, subjetivada e vivenciada por cada pessoa.

As formas de liberação e controle que se inscrevem no corpo dizem respeito desde as formas de cuidado corporal até as formas de interações sociais que se estabelecem. 
No cinema encontramos dois bons exemplos que problematizam essas questões. O filme "O Demolidor" lançado em (1993) constitui-se de uma história de ação que acontecia num futuro não muito distante, mais especificamente no ano de 2032. Mas, é o modo de vida das pessoas (que vivem dos avanços de seu tempo) que chama atenção, as pessoas não se tocam nem para um cumprimento de mãos. A prática do sexo também se dava sem contato corporal; assim, todos os cidadãos que desejassem praticálo acoplavam a cabeça um tipo de mecanismo eletrônico, esse mecanismo reproduzia imagens sensuais que provocariam as sensações provenientes dessa prática, numa espécie de virtualização do sexo. Os personagens desse futuro mostram aversão/repulsa com a troca de "fluídos" e com o risco de contaminação de doenças presentes na "arcaica" forma de praticá-lo. Essas questões tratam, em última instancia, do desejo de afastamento de nossa animalidade, além do controle da natalidade, questões estas colocadas em pauta muito antes da realidade virtual, mas que parecem ter uma possibilidade de controle associado ao prazer e a liberdade de uma prática que pode se constituir longe dos riscos.

"Strange Days", filme de 1992, apresenta a possibilidade de acessar a experiência de outras pessoas por meio de uma gravação. Desenvolvendo a idéia de que a experiência registra-se na memória, o filme trabalha com um dispositivo que conectado ao cérebro seria capaz de gravar a experiência. E quando alguém adquirisse acesso à gravação seria plugado a mesma por um aparelho acoplado a cabeça e de alguma forma poderia reviver, corporalmente, a experiência de outra pessoa e não apenas assisti-la. A idéia do filme é a comercialização da experiência do outro; as mercadorias são constituídas por parcelas da vida de outrem. O risco aqui é de um processo de docilização, não mais dos corpos, já efetivado, mas da experiência mesma; da constituição de uma experiência do mundo de segunda mão, efetivada por outros e consumida passivamente, tudo em nome do prazer. Outro elemento que pode ser problematizado a partir do filme é a possibilidade de criação de um mecanismo que se apropria das funções de registro da memória, pois segundo Benjamin (1994) é na memória onde se registra a experiência. Dessa forma, a memória como um espaço/tempo característico que acondiciona a experiência já não seria tão relevante e passaria a ser condicionada desde fora.

Em ambos os filmes, a experiência virtual promove diferentes formas de liberação e potencialidades 
de controle a serem inscritas no corpo, conformando parte substancial da vida em sociedade. Apesar de serem provenientes de um exercício futurístico no cinema, esses elementos já se encontram em curso, com o Second Life constituindo-se como um bom exemplo, mesmo que ainda não estejam desenvolvidas as tecnologias apontadas nos filmes, é importante lembrar que, em grande medida, a arte antecipa a vida.

As implicações dessa nova forma de liberação e da constituição de novos mecanismos de controle sobre a experiência, por não se identificar conseqüências sociais objetivas, não estão totalmente explícitas, pois ainda estão sendo escritas na história do presente. Mesmo que estas práticas sejam determinadas pela lógica de mercado, a experiência que delas resulta vai sendo cotejada com a singularidade do sujeito; dado que representa uma positividade, na medida em que ainda se encontra em aberto um espaço para a constituição de outras formas de relações humanas.

\section{Elementos da experiência}

Compreendemos que nem tudo o que as pessoas fazem ou o que acontece com elas pode ser considerado uma experiência. Concordamos com Bondía (2002, p.21), compreendendo que a "experiência [segundo a tradução do seu significado em diferentes línguas] é o que nos passa, o que nos acontece, o que nos toca. Não o que se passa, não o que acontece, ou o que toca".

Benjamim (1994) para diferenciar o que se passa do que nos passa usa os termos vivência e experiência. Enquanto a primeira abarca de forma geral tudo o que se passa no cotidiano (virtual ou não) e que não deixam marcas nas pessoas por sua superficialidade, a segunda refere-se aos momentos vividos por uma pessoa que são retidos na memória pela intensidade como a toca (consciente ou inconscientemente).

A questão pela qual essa diferenciação passa a ser importante nesse texto, segundo o que compreendemos da perspectiva conceitual desses autores, é refletirmos se o processo social que estamos observando constitui-se como o declínio da experiência e uma intensificação de meras vivências, processo para o qual as práticas corporais virtualizadas estariam contribuindo.

Nunca antes foi presenciada a emergência sucessiva de novos e diferentes acontecimentos em espaços de tempo tão curtos como na atualidade e, concomitantemente, a indiferença aos fatos parece ser uma marca cotidiana. "A cada dia se passam muitas coisas, porém, ao mesmo tempo, quase nada aconte- 
ce. Dir-se-ia que tudo o que passa está organizado para que nada nos aconteça" (BONDÍA, 2002, p.21) O modo como se organiza a vida, sobretudo a partir dos avanços da tecnologia e da ideologia do consumo, comprimem as chances de experiência.

Enquanto na tese prometéica objetiva-se dominar a natureza culminando na dominação de si mesmo, na tese fáustica o corpo pode ser descartado de antemão. Ambas as teses que amparam o avanço da tecnociência mostravam, inicialmente, a intenção de atuar em prol dos interesses humanos. No seu desenrolar histórico trouxeram, ambiguamente, a intensificação do processo de coisificação das relações humanas, talvez, inclusive no âmbito das práticas corporais virtualizadas, o que, pela intensidade e amplitude potencializando o processo de perda da experiência que se manifesta em outras instancias da vida.

A experiência virtual não aparece apenas como negatividade, pois traz consigo também os artefatos da tecnociência como novas possibilidades de expandir as formas de percepção e apreensão do mundo e, por isso, apresenta outras possibilidades de experenciar situações que, de outro modo, seriam improváveis. (LE BRETON, 2003).

Algumas questões se colocam em nossa reflexão: De que natureza é a experiência [no sentido que a concebemos] na realidade virtual ou se, de outro modo, não seria mais adequadamente compreendida como vivencia? Dada a extensão da realidade virtual na vida de crianças, jovens e adultos, não apenas em termos de tempo, como de intensidade e rompimento de limites e modos tradicionais de vida, em que medida vem se constituindo outro processo de formação humana?

A resposta a esta questão não parece ser simples ou colocada de forma taxativa, inclusive porque se trata de um universo emergente, mas de fato parece possível tanto estabelecer um rumo em direção a perda da experiência, quanto ir ao encontro de algo totalmente diferente, ambas os processos concomitantemente e, em certa medida, paradoxais. Todas essas possibilidades parecem estar colocadas, dado que a sociedade encontra-se em fase de alterações significativas que podem gerar outro modo de ser humano inclusive dependente do tipo de experiência (ou não) que as pessoas possam ter no contato com os jogos e realidades virtuais.

A constituição da aptidão à experiência consistiria essencialmente na conscientização e, desta forma, na dissolução desses mecanismos de repressão e dessas formações reativas que 
deformam nas próprias pessoas sua aptidão à experiência. Não se trata, portanto, apenas da ausência de formação, mas da hostilidade frente à mesma, do rancor frente àquilo de que são privadas. Este teria de ser dissolvido, conduzindo-se as pessoas àquilo que no intimo todas desejam. (ADORNO, 1995, p.150).

A experiência por meio da virtualização do corpo e das práticas corporais incorpora diferentes noções de espaço e tempo que alteram elementos que, até então, faziam parte da constituição da experiência da forma como há concebemos tradicionalmente. Trata-se de incorporar na reflexão; constituem-se novos elementos que interpelam o conceito de experiência e que precisam ser considerados em todas as suas possibilidades. Da constituição da experiência, importante lembrar das dimensões individual e coletiva do processo de construção dos conhecimentos, marcados por tradições, costumes, normas e valores que marcavam as interações sociais no tempo histórico, cujo conjunto definiam a própria condição da experiência, como indica Thompson (1987).

Cabe refletir se estas condições estão mantidas na realidade virtual ou se constituíram outros elementos que irão marcar a formação humana, distante dessas práticas sociais, até então, considerados significativos, inclusive com essa nova cisão entre corpo e experiência. É fato que os conhecimentos advindos da filosofia e das ciências humanas os quais embasam, também, o campo da Educação Física tentem desconstruir a concepção dualista corpo-mente/espírito que permanece em voga na modernidade. Mesmo quando esta dicotomia toma seu auge nas ações sobre o corpo, pode se dizer que havia sempre um corpo como resistência, um ser humano em sua inteireza por trás do que lhe era imposto e, em sua singularidade, podia achar um espaço para experenciar as práticas corporais. Ao dissociar corpo e experiência o movimento humano constituinte dessas práticas é reduzido ou pode ser descartado como foco da intencionalidade humana.

De forma ambígua, ao projetar-se no ciber-espaço o humano busca movimentar-se de forma alargada e muito mais acelerada ampliando suas possibilidades de conhecer o mundo, de experencia-lo.

Feres Neto (2001, p. 69) aponta dois aspectos dos novos elementos colocados para se pensar a experiência na realidade virtual, onde o primeiro constitui-se como

(...) um embaralhamento entre praticar e assistir, presente (...) 
nas possibilidades integrativas proporcionadas pelo videogame, e o segundo pode ser caracterizado como uma intensificação da experiência vital, que paradoxalmente corresponde a uma profunda atualização corporal no mesmo momento em que o corpo se desterritorializa, se vetoriza, características da prática de esportes radicais.

Cabe ressaltar que ao entrar no ciber-espaço a pessoa passa a ser a protagonista, um dado sedutor, mas também é praticante na mesma medida em que é coadjuvante quando separa corpo e experiência. Esta experiência, contudo, vai marcar o corpo e as relações que estabelecerá com a vida e com a sociedade.

Um exemplo no campo da Educação Física da inscrição da experiência virtual sobre o corpo é o surgimento dos ciberatleta a partir de uma cibercultura. O termo ciberatleta é utilizado para designar praticantes de jogos virtuais, geralmente àqueles usuários da internet (COSTA \& BETTI, 2006). A constituição dessa figura numa visão ampliada sobre o esporte o compõe e ao mesmo tempo, interfere, exigindo reconstruir a própria representação que temos das práticas corporais.

Considerando a ambigüidade presente na intencionalidade do movimento no ciberespaço, nessa circularidade interpela o agir, fazendo com que possam surgir diferentes formas de interação para a Educação Física, especialmente, a partir das novas relações que podem e serão estabelecidas no mundo virtual, do qual não é mais possível retroceder.

O virtual além de gerar novas descobertas e tendências, por vezes coisificantes, em relação a imagem de corpo e as práticas corporais, também tem meios de gerar esclarecimento. Nessa questão, outro problema no âmbito da experiência configura-se na relação com a velocidade com que chegam as informações às pessoas, não propiciado tempo para assimilação, reflexão e re-criação do conteúdo dessas informações. Nesse rápido processo no qual chega uma multiplicidade de informações, o receptor não é de todo passivo e pode re-criar e re-significar, inclusive a si mesmo, num movimento dialético que ainda não compreendemos adequadamente.

Esses são alguns apontamentos iniciais que gostaríamos de fazer, os quais se configuram mais como questionamentos do que como afirmações. Compreendemos que para a Educação Física e o Lazer, preocupados com a experiência, é vital problematizar o movimento humano e as práticas corporais na sua relação com 
o virtual e com a virtualização. O caminho por onde trilhar, tanto do ponto de vista da reflexão teórico como da investigação empírica, ainda estão sendo construídos. Uma indicativa chave para esse caminho parece ser o esclarecimento com vistas à emancipação em busca por conhecer o que constitui as condições para a experiência, assim como também aquilo que a limita.

São muitas as incógnitas que permeiam essa discussão, inclusive considerando a impossibilidade de conhecer e dominar completamente a physis humana, como dito anteriormente (SILVA, 2001), o que pode ser um reconhecimento da positividade do corpo e das práticas corporais na perspectiva de emancipação humana.

\section{Referência}

ADORNO, T. W. Educação e Emancipação. Editora Paz e Terra: Rio de Janeiro, 1995.

BAUMAN, Z. Modernidade Líquida; tradução, Plínio Dentzien. Rio de janeiro: Jorge Zahar Ed., 2001.

BECK, U. La Sociedad del Riesgo: hacia una nueva modernidad. Barcelona: Paidós, 1998.

BENJAMIM, W. Magia, arte e política: ensaios sobre literatura e história da cultura. $7^{\mathrm{a}}$. ed. São Paulo: Brasiliense, 1994.
BONDÍA, J. L. Notas sobre a experiência e o saber da experiência. In: Rev. Brasileira de Educação. 2002. n. 19

COSTA, A. Q.; BETTI, M. Mídias e jogos: do virtual para experiência corporal educativa. Revista Brasileira de Ciências do Esporte. v. 27, n. 2, p. 165-178, jan. 2006.

ELIAS, N. A Busca da Excitação. Lisboa: Difel, 1992.

FERES NETO, A. A virtualização do esporte e suas novas vivências eletrônicas. 2001. 117 f. Tese (Doutorado em Educação) Faculdade de Educação, Universidade Estadual de Campinas, Campinas, 2001.

KENSKI, V. M. Tecnologias e ensino presencial e a distância. São Paulo: Papirus, 2003.

LE BRETON, D. Adeus ao Corpo: Antropologia e Sociedade. $2^{\text {a }}$. ed. Campinas, SP: Papirus, 2003.

LÉVY, P. Ciberdemocracia. Lisboa. Ed. Odile Jacob, 2002.

LÉVY, P. O que é o virtual? São Paulo: Ed. 34, 1996.

MASCARENHAS, F. O pedaço sitiado: cidade, cultura e lazer em tempos de globalização. In: Revista Brasileira de Ciência do Esporte. Campinas, 2003. V. 24, n.3.

PAGNI, P. As contribuições da história para a educação física: um ponto de vista. Revista Brasileira 
de Ciências do Esporte, v. 17, n. 2, p. 153-160, jan. 1996.

PAIVA, F. S. L. Notas para pensar a Educação Física a partir do conceito de campo. Perspectiva Revista do Centro de Ciências da Educação da UFSC, Florianópolis, v. 22- Es, p. 051-082, 2004

RIVOLTELLA, P. C. A formação da consciência civil entre o "real" e o "virtual". In: FATIN, M.; GIRARDELLO, G. (Orgs.) Liga, roda e clica: Estudos em mídia, cultura e infância. Campinas/SP: Papirus, 2008. (Coleção Ágere)

SETZER, V. W. Meios eletrônicos e educação: uma visão alternativa. São Paulo: Escrituras Editora, 2001.

SIBILIA, P. O homem pós-orgânico: corpo, subjetividade e tecnologias digitais. Rio de Janeiro: Relume Dumará, 2002.

SILVA, A. M. A natureza da physis humana: indicadores para o estudo da corporeidade. In: SOARES, C. L. Corpo e história. Campinas-SP: Autores Associados, 2001.

SOARES, C. L. Educação física: raízes européias e Brasil. Campinas, SP: Autores Associados, 1994.

. Imagens da educação no corpo: um estudo a partir da ginástica francesa no século
XIX. Campinas, SP: Autores Associados, 1998.

SPINK, M. J. P. . Os Contornos do Risco na Modernidade Reflexiva: Considerações a Partir da psicologia Social. Psicologia e Sociedade, São Paulo, v. 12, n. 1/2, p. 156-173, 2001.

SPINK, M. J. P. ; CAÑAS, A. ; SOUZA, D.T. ; GALINDO, D. . Onde está o risco? Os seguros no contexto do turismo de aventura. Psicologia e Sociedade, Porto Alegre, v. 16, n. 2, p. 81-89, 2004.

SPINK, M. J. P. . Posicionando pessoas como aventureiros potenciais: imagens de riscoaventura em matérias de revista. Psicologia e Sociedade, v. 20, p. 50-60, 2008.

THOMPSON, E. P. A formação da classe operária inglesa. Rio de Janeiro, Paz e Terra, 1987.

VAZ, A. F. Treinar o corpo, dominar a natureza: notas para uma análise do esporte com base no treinamento corporal. Cad. CEDES, Campinas, v. 19, n. 48, 1999.

Recebido: agosto/2010. Aprovado: outubro/2010. 